\title{
CORRESPONDENCE
}

\section{SENILE ENTROPION}

\section{To the Editorial Committee of the British Journal of OpHTHALMologY}

SIRS,-I was interested to read Mr. W. S. Foulds's paper on the surgical cure of senile entropion (Foulds, 1961), but I question his views on the aetiology and consequently the treatment of this condition.

The primary cause of senile entropion is the accumulation of orbicularis fibres near the lid margin. This was suggested by Kettesy (1948) and has been fully amplified by Jones (1960). Atrophy of orbital fat and laxity of the lower lid structures, including tarsus, are purely secondary features. It is the atrophy of the fine connective tissue which normally keeps the orbicularis muscle in its proper relation to the tarsal plate, allowing free movement of the orbicularis over it, that is the primary causative factor in senile entropion.

After all, enucleation produces the most severe form of loss of support for the lower lid, yet entropion in such cases is very rare. Many old patients have extremely lax lower eyelids without entropion and it is impossible to produce it in them. Conversely, entropion is often present in patients in whom atrophy of orbital fat and laxity of lid structures is obviously not present.

The success of the majority of entropion operations depends on resulting fibrosis and the effect that this has on preventing vertical movement of the orbicularis fibres over the tarsal plate. When the pathology is clear, the success or failure of all these operations can easily be understood.

No one denies the success of Wheeler's operations or even of skin and muscle and cauterizing procedures at times, either temporarily or permanently. Their efficacy depends on their effect in fixing the orbicularis on a horizontal axis. Wedge resections of the tarsus as advocated by Butler (1948) and Fox (1951) have a similar effect, because the orbicularis is interfered with and subsequent fibrosis prevents free movement of the muscle over the tarsus. It is not the resection of the tarsus itself that corrects the entropion. The disadvantage of these operations is that they always affect the size of the palpebral aperture to some extent and they are also time-consuming.

The type of procedure for correction of entropion as described by Wies (1954) places a physical barrier in front of the tarsal plate and prevents the free movement of the orbicularis over it.

The Wies type operation is extremely simple and effective (McFarlane, 1956; Ffooks, 1961) and produces no post-operative distortion of the lid or palpebral aperture. I believe that this procedure attempts to restore, as nearly as possible, the basic physiology of the eyelid, and is the method of choice when operating on most types of entropion.

Yours faithfully,

ROYAL INFIRMARY

O. O. F. FFOOKS.

SHEFFIELD, 6.

October 31, 1961.

\section{REFERENCES}

BUtLer, J. B. V. (1948). Arch. Ophthal. (Chicago). 40, 665.

FFOOKs, O. O. F. (1961). Brit. J. Ophthal., 45, 130.

FouLDs, W. S. (1961). Ibid., 45, 678.

Fox, S. A. (1951). A.M.A. Arch. Ophthal., 46, 424.

JONES, L. T. (1960). Amer. J. Ophthal., 49, 29.

KeTtesY, A. (1948). Brit. J. Ophthal., 32, 311.

MCFARLANE, D. C. (1956). Amer. J. Ophthal., 41, 657.

WIES, F. A. (1954). J. int. Coll. Surg., 21, 758. 


\section{To the Editorial Committee of the British Journal of OphTHALmology}

Sirs,-In reply to Mr. O. O. F. Ffooks's letter, I note his remarks, and thank him for his interest.

While I do not disagree that accumulation of orbicularis fibres near the lid margin may be a factor in the production of senile entropion, this is but one of the manifestations of atrophy and laxity affecting the connective tissues of the lid in this condition. The main feature is lack of the normal apposition of the tarsal plate to the globe. It is this defect which is fully corrected by the operation I have described, although, as Ffooks points out, the operation may also correct any abnormal mobility of the orbicularis muscle at the same time.

In my experience, senile entropion does not occur in the absence of lid laxity (while incidentally, entropion is a common finding after enucleation if a satisfactory prosthesis is not worn).

At operation, the immediate correction of the defect following tightening of the tarsal plate sutures makes it obvious that the tarsectomy is mainly responsible for the success of the operation. McFarlane (1956), in reviewing operations for entropion, regarded the Weis operation as satisfactory in 78 per cent. of cases, most of the failures being due to overcorrection. In Ffooks's own series there were two unsatisfactory cases in 35, over a follow-up period of 6 to 12 months.

During the past 5 years, 54 cases of entropion have been treated by the technique which I advocate, without a single recurrence, or any tendency to overcorrection of the defect. The operation is, I would say, easier to perform than the Weis operation, and usually takes less than 10 minutes. In none of the cases operated on has there been any noticeable reduction in the size of the palpebral aperture, and I am convinced that the method is one well worth further trial in the treatment of this common but distressing complaint.

Yours faithfully,

173 HUNTINGDON ROAD, W. S. Foulds.

CAMBRIDGE.

July 26, 1962.

\section{BOOK REVIEWS}

System of Ophthalmology. Vol. VII. The Foundation of Ophthalmology. Heredity, Pathology, Diagnosis, and Therapeutics. STEWART DuKe-Elder (Editor). 1961. Pp. 829, 471 figs, bibl. Kimpton, London. (£7).

It may seem strange that the seventh volume of this series should follow in chronology the publication of volumes one and two but, as the Editor points out in his preface, the greatest need would appear to be for the revision of the clinical sections of his Text-book. These are not only out of print but inevitably with the tempo of process in ophthalmology, as in other branches of medicine, to a large extent out of date. Anachronous though its emergence may be, the seventh volume is none the less welcome, for-as is hardly necessary to say-it maintains the high standard of excellence set by its two predecessors and, perhaps even more than they, whets the appetite for what is to come. 